\title{
Clinical Impact of Genetic Studies in Lethal Inherited Cardiac Arrhythmias
}

\author{
Wataru Shimizu, MD
}

\begin{abstract}
Over the past decade, molecular genetic studies have established a link between a number of inherited cardiac arrhythmias, including congenital long QT syndrome (LQTS) and Brugada syndrome (BrS), and mutations in genes encoding for ion channels or other membrane components. Twelve forms of LQTS have been identified in $50-70 \%$ of clinically affected patients. Genotype-phenotype correlations have been rigorously investigated in LQT1, LQT2 and LQT3 syndromes, which constitute more than 90\% of genotyped LQTS patients, enabling stratification of risk and effective treatment of genotyped patients. Genotype-specific triggers for both the cardiac events and the clinical course have been reported, and genotype-specific therapy has been already introduced. More recently, mutation site-specific differences in the clinical phenotype have been reported in LQT1 and LQT2 patients, indicating the possibility of mutation site-specific management or treatment. In contrast, only one-third of BrS patients can be genotyped, and data on genotype-phenotype relationships in clinical studies are limited. A Haplotype B consisting of 6 individual DNA polymorphisms within the proximal promoter region of the SCN5A gene was recently identified only in Asians (frequency 22\%). Individuals with Haplotype B show significantly longer duration of both PQ and QRS than those without Haplotype B, indicating that Haplotype B likely contributes to the higher incidence of BrS in Asian populations. (Circ J 2008; 72: 1926-1936)
\end{abstract}

Key Words: Brugada syndrome; Genotype; Ion channel; Long QT syndrome; Sudden death

$\Delta$

dvances in molecular genetic studies since the late 1990s have established a link between a number of lethal inherited cardiac arrhythmias and mutations in genes encoding for ion channels or other membrane components!-11 Most inherited cardiac arrhythmias have been linked to ion channelopathies giving rise to primary electrical diseases, including congenital and acquired long QT syndrome (LQTS), ${ }^{1,2}$ Brugada syndrome $(\mathrm{BrS})$, , progressive cardiac conduction defect (Lenegre disease) ${ }_{4}^{4}$ catecholaminergic polymorphic ventricular tachycardia (CPVT), 56 arrhythmogenic right ventricular cardiomyopathy? familial atrial fibrillation, familial sick sinus syndrome, ${ }^{9}, 10$ and short QT syndrome ${ }^{11}$ (Table1). Among these primary electrical diseases, congenital LQTS is the Rosetta stone for understanding the genetic basis of inherited cardiac arrhythmias, ${ }^{2}$ because the responsible mutations can be identified in multiple genes encoding different ion channels or membrane adaptor in approximately 50-70\% of clinically affected patients. Similarly, causative mutations can be detected in the ryanodine receptor $(R y R 2)$ gene or calsequestrine gene in more than $60 \%$ of clinically diagnosed CPVT patients $!^{3} \mathrm{BrS}$ is another common inherited cardiac arrhythmia syndrome, and responsible mutations have been identified in 6 genes; however, only one-third of patients with BrS can be genotyped. Responsible mutations have been identified much less

(Received October 6, 2008; accepted October 9, 2008; released online November 4, 2008)

Division of Cardiology, Department of Internal Medicine, National Cardiovascular Center, Suita, Japan

Mailing address: Wataru Shimizu, MD, Division of Cardiology, Department of Internal Medicine, National Cardiovascular Center, 5-7-1 Fujishiro-dai, Suita 565-8565, Japan. E-mail: wshimizu@hsp.ncvc. go.jp

All rights are reserved to the Japanese Circulation Society. For permissions, please e-mail: cj@j-circ.or.jp in other inherited cardiac arrhythmias, so genetic screening is much more challenging. This review focuses on the recent progress in molecular genetic studies and their clinical impact on the inherited cardiac arrhythmias, congenital LQTS and BrS.

\section{Congenital LQTS}

Prolonged QT interval and polymorphic ventricular tachycardia, known as torsades de pointes (TdP), recorded on an electrocardiogram (ECG) are trademarks of congenital LQTS (Fig 1)!2,14 The clinical diagnosis of congenital LQTS is mainly based on the corrected (QTc) interval at rest, and cardiac events such as syncope, aborted cardiac arrest and sudden cardiac death because of TdP ${ }^{4}$ However, the ECG diagnosis at rest has long been reported to miss some patients affected by congenital LQTS, as evidenced

Table 1 Genotype of Inherited Cardiac Arrhythmias

\begin{tabular}{|c|c|c|c|}
\hline Congenital LQTS & $\begin{array}{l}\text { Romano-Ward } \\
\text { JLN }\end{array}$ & $\begin{array}{l}(1995-) \\
(1997-)\end{array}$ & $\begin{array}{l}\text { CLQT 1-12 } \\
J L N 1,2\end{array}$ \\
\hline Acquired LQTS & & (1997-) & ALQTS 1-2 \\
\hline$B r S$ & & (1998-) & $\operatorname{BrS} 1-2$ \\
\hline$P C C D$ & & (1999-) & PCCD 1 \\
\hline$C P V T$ & & (2001-) & CPVT 1, 2 \\
\hline Familial SSS & & (2003-) & $\operatorname{SSS} 1,2$ \\
\hline Familial AF & & (2003-) & $A F 1-5$ \\
\hline$A R V C$ & & (2004-) & ARVC 1-5 \\
\hline$S Q T S$ & & (2004-) & SQTS 1-5 \\
\hline
\end{tabular}

LQTS, long QT syndrome; JLN, Jervell \& Lange-Nielsen; BrS, Bugada syndrome; PCCD, progressive cardiac conduction defect; $C P V T$, catecholaminergic polymorphic ventricular tachycardia; SSS, sick sinus syndrome; AF, atrial fibrillation; $A R V C$, arrhythmogenic right ventricular cardiomyopathy; SQTS, short QT syndrome. 
A QT $=600 \mathrm{~ms} \quad$ QTc $=548 \mathrm{~ms}$
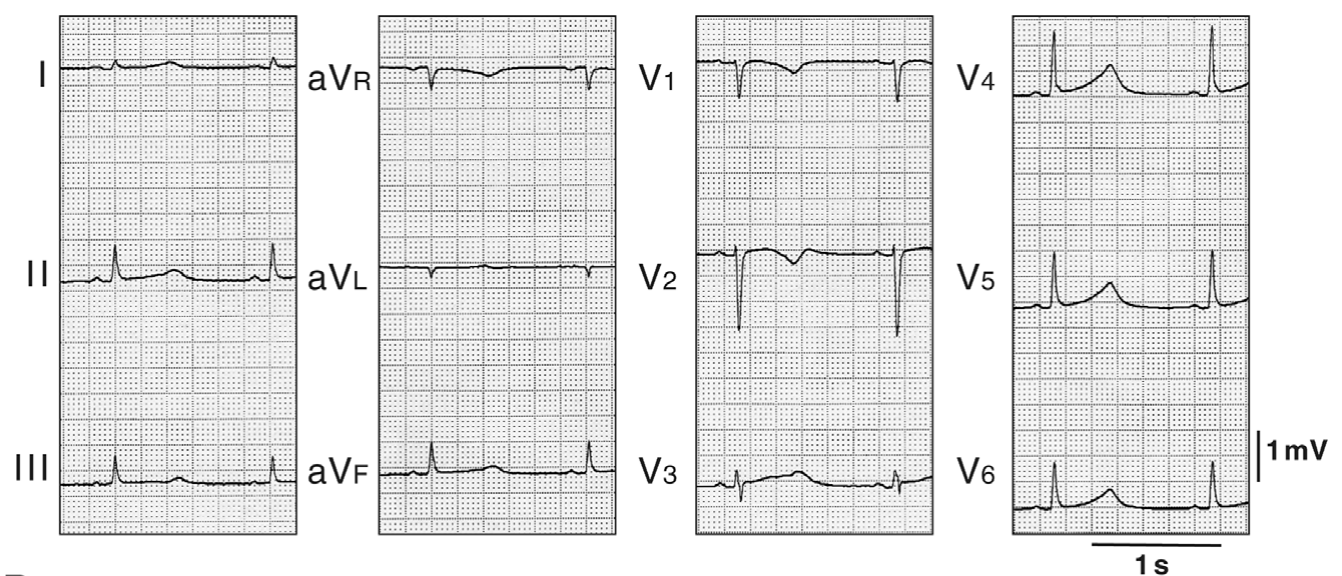

B Torsade de Pointes

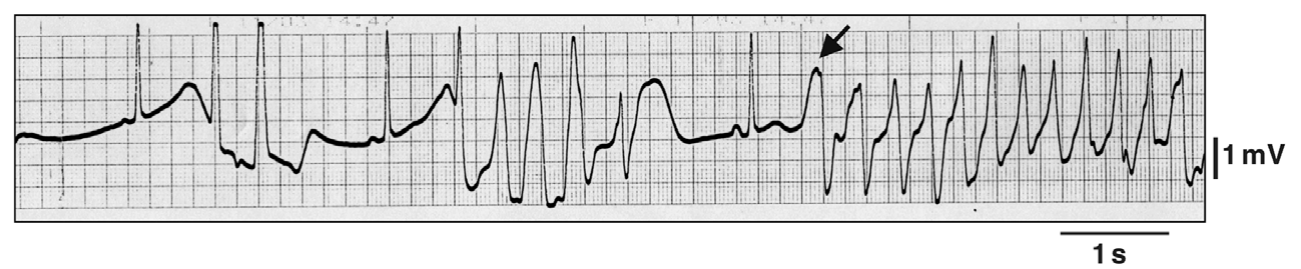

Fig 1. Twelve-lead electrocardiogram and torsades de pointes (TdP) in a patient with LQT2 syndrome. (A) Remarkable QT prolongation (corrected QT $(\mathrm{QTc})$ interval $=548 \mathrm{~ms}$ ) and a low amplitude $\mathrm{T}$ wave with a notched configuration are seen. (B) TdP was induced following the typical short-long-short initiating sequence.

Table 2 Defect of Ion Channel or Membrane Adaptor Responsible for Congenital LQTS

\begin{tabular}{lccc}
\hline \hline Loci & Chromosome & Gene & Ion channel \\
\hline Romano-Ward syndrome & & & \\
LQT1 & $11(11 p 15.5)$ & KCNQ1 & $I_{K s}$ \\
LQT2 & $7(7 q 35-36)$ & KCNH2 & $I_{K r}$ \\
LQT3 & $3(3 p 21-23)$ & SCN5A & $I_{N a}$ \\
LQT4 & $4(4 q 25-27)$ & Ankyrin-B & Na-K ATPase, INa-Ca \\
LQT5 & $21(21 q 22.1-q 22.2)$ & KCNE1 & $I_{K s}$ \\
LQT6 & $21(21 q 22.1-q 22.2)$ & KCNE2 & $I_{K r}$ \\
LQT7 & $17(17 q 23.1-24.2)$ & KCNJ2 & $I_{K 1}$ \\
LQT8 & $12(12 p 13.3)$ & CACNA1C & $I_{\text {Ca-L }}$ \\
LQT9 & $3(3 p 25)$ & CAV3 & $I_{N a}$ \\
LQT10 & $11(11 q 23.3)$ & SCN4B & $I_{N a}$ \\
LQT11 & $7(7 q 21-q 22)$ & AKAP-9 & $I_{K s}$ \\
LQT12 & $20(20 q 11.2)$ & SNTA1 & $I_{N a}$ \\
JLNyndrome & & & \\
JLN1 & $11(11 p 15.5)$ & KCNQ1 (homozygous) & $I_{K s}$ \\
JLN2 & $21(21 q 22.1-q 22.2)$ & KCNE1 (homozygous) & $I_{K s}$ \\
\hline
\end{tabular}

Abbreviations see in Table 1.

by syncopal events occurring among family members with a "normal" QT interval; 15 therefore, provocative testing using catecholamine infusion or exercise was developed to unmask concealed forms of congenital LQTS, before genetic screening became available! ${ }^{16-20}$

\section{Genotype in Congenital LQTS}

Because familial forms of congenital LQTS have long been recognized, a genetic background (inheritance) has long been expected. Since the first 2 genes responsible for LQTS were identified in $1995^{21,22}$ molecular genetic studies have revealed 12 forms of Romano-Ward-type congenital LQTS caused by mutations in the genes of the potassium, sodium and calcium channels or the membrane adapter located on chromosomes $3,4,7,11,12,17,20$ and 21 (Table2) ${ }^{23-31}$ Mutations in KCNQ1 and KCNE1, the $\alpha$ and $\beta$ subunits of the potassium channel gene, are responsible for defects (loss of function) in the slowly activating component of the delayed rectifier potassium current (IKs) underlying the LQT1 and LQT5 forms of LQTS32,33 Mutations in $K C N H 2$ and $K C N E 2$ cause defects in the rapidly activating component of the delayed rectifier potassium current (IKr), which is responsible for the LQT2 and LQT6 forms ${ }^{21,34}$ Mutations in SCN5A, the gene that encodes the $\alpha$ subunit of the sodium channel, result in an increase (gain of function) in the late sodium current ( $\mathrm{INa}$ ), which is responsible for LQT322 Mutations in KCNJ2 encoding the inward rectifier potassium current (IK1) underlie Andersen's 
A

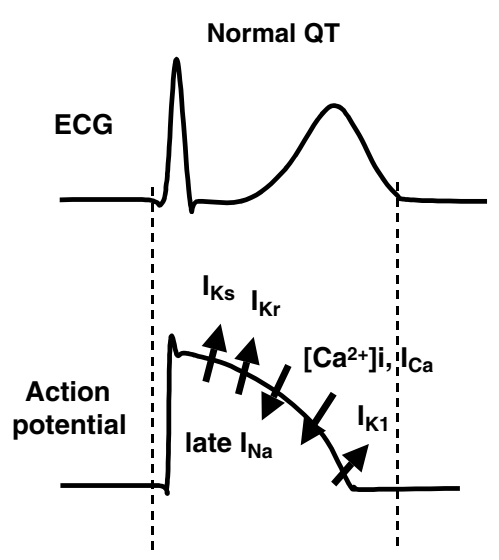

B

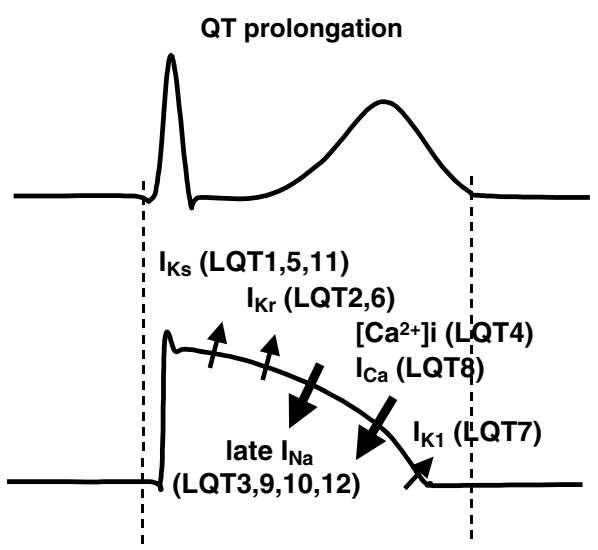

Fig 2. Ionic mechanism of QT prolongation in the LQT1 to LQT12 forms. Decreases in the outward potassium currents (IKs, IKr, IKl) or increases in the inward sodium or calcium current (late INa, ICa-L) prolong the action potential duration, resulting in prolongation of the QT interval in all 12 genetic forms. ECG, electrocardiogram. syndrome (LQT7), in which QT prolongation and ventricular arrhythmias are accompanied by periodic paralysis and dysmorphic features ${ }^{24}$ A mutation in Ankyrin-B, a member of a family of versatile membrane adapters, produces intracellular calcium overload, which underlies LQT4 syndrome and is associated with sinus bradycardia and paroxysmal atrial fibrillation, in addition to QT prolongation25 A mutation in CACNAIC is reported to be responsible for the defect in the L-type calcium current (ICa-L) underlying the LQT8 form, an arrhythmia disorder associated with dysfunction in multiple organ systems, including congenital heart disease, syndactyly, immune deficiency, and autism ${ }^{26} C A V 3$ encoding caveolin-3 and $S C N 4 B$ encoding $N a v B 4$, an auxiliary subunit of the cardiac sodium channel, are also reported to be associated with the LQT9 and LQT10 forms, respectively. Mutations in both genes result in a gain of function of late INa, thus causing an LQT3-like phenotype ${ }^{27,28}$ AKAP-9 encoding Yotiao, which assembles $K C N Q 1$, is reported to be linked to the LQT11 form. ${ }^{29}$ Most recently, we and others reported mutations in a cytoskeletal protein syntrophin- $\alpha 1$ (SNTA1), which interacts with the cardiac sodium channel, thus resulting in an LQT3-like phenotype (LQT12) 30,31 At least some cases of sudden infant death syndrome (SIDS) are attributable to congenital LQTS 35 Mutations in $S C N 5 A, 35,36$ $C A V 33{ }^{37} \mathrm{KCNQ}^{38}$ and $\mathrm{KCNH} 2^{38}$ are reported to be associated with SIDS. As a common mechanism, decreases in the outward potassium currents ( $\mathrm{IKs}$, IKr, IK1) or increases in the inward sodium or calcium current (late INa, ICa-L) prolong the action potential duration (APD), resulting in prolongation of the QT interval, a common phenotype in LQTS in all 12 genetic forms (Fig 2). Among the 12 forms, the LQT1 and LQT2 syndromes are the most common genetic variants, and each accounts for approximately $40 \%$ of genotyped patients; LQT3 syndrome accounts for approximately $10 \%$ of genotyped patients 23 Because the LQT1, LQT2 and LQT3 syndromes constitute more than $90 \%$ of genotyped patients with LQTS, the genotype-phenotype correlation has been rigorously investigated, and enables stratification of risk and effective treatment of genotyped patients with these 3 major forms ${ }^{23}$

Autosomal recessive forms (JLN1 and JLN2) of the Jervell \& Lange-Nielsen syndrome are associated with neurosensory deafness and generally more prominent QT prolongation and more severe ventricular arrhythmias compared with the autosomal dominant forms of the Romano-Ward syndrome 39 JLN1 and JLN2 are reported to be responsible for homozygous or compound heterozygous mutations in the $K C N Q 1$ and/or KCNE1 genes. Approximately $8 \%$ of LQTS patients carries homozygous or compound heterozygous mutations in 2 LQTS-causing genes, and are reported to have longer QTc and 3.5-fold more risk of cardiac arrest. ${ }^{40}$ On the other hand, an autosomal recessive form of LQT1 syndrome without neurosensory deafness was reported by Priori et al. ${ }^{41}$ Some single mutations in the SCN5A gene are reported to cause multiple phenotypes, such as BrS, sick sinus syndrome, and conduction disease, in addition to the LQT3 phenotype.42,43

\section{Genotype-Phenotype Relationships in Congenital LQTS}

T-Wave Morphology on the ECG A series of experimental studies using arterially-perfused canine wedge preparations have revealed that intrinsic transmural electrical heterogeneity of ventricular repolarization from the epicardial, mid-myocardial to the endocardial cells contributes to ST-T morphology and the QT interval on ECG, especially in the left precordial (V4-6) leads, which are thought to reflect the potentials of the left ventricular anterolateral wall44-46 Under normal conditions, repolarization of the epicardial action potential occurs first, coinciding with the peak of the normal $\mathrm{T}$ wave, whereas repolarization of the longest action potential in the mid-myocardial layer coincides with the end of the $\mathrm{T}$ wave 44 Repolarization of endocardial cells usually occurs between repolarization of the epicardial and mid-myocardial cells.4 ${ }^{4}$ The amplified transmural electrical heterogeneity of ventricular repolarization associated with differential modification of ionic currents in each cell type, which is caused by mutations in each LQTS gene, results in genotype-specific T-wave morphology on the ECG 44,45 Moss et al first proposed genotype-specific T-wave morphology in genotyped patients with the LQT1, LQT2 and LQT3 forms in 199547 Broad-based, prolonged $\mathrm{T}$ waves are more commonly observed in LQT1 syndrome; low-amplitude $\mathrm{T}$ waves with a notched or bifurcated configuration are more frequently observed in LQT2; and lateappearing $\mathrm{T}$ waves with a prolonged isoelectric ST-segment are more specific in LQT3 syndrome. The genotype-specific T-wave pattern was further evaluated by Zhang et al in 2000, and numerous exceptions are reported for all 3 genotypes. 48

Natural History Zareba et al suggested a higher cumulative probability of cardiac events in LQT1 and LQT2 patients than in LQT3 patients.9 More than $50 \%$ of patients 
A LQT1

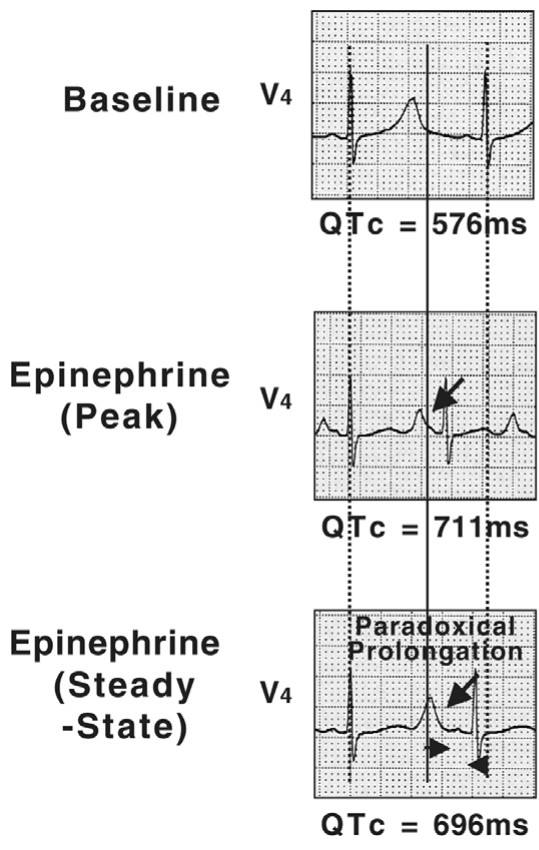

B LQT2

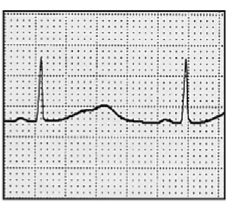

$Q T c=592 \mathrm{~ms}$

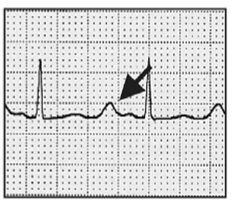

$\mathrm{QTc}=684 \mathrm{~ms}$

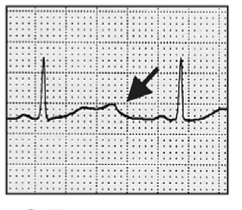

$\mathrm{QTC}=611 \mathrm{~ms}$
C LQT3

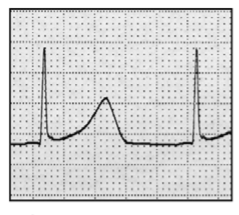

$Q T c=560 \mathrm{~ms}$

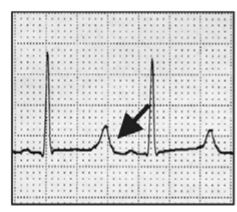

$\mathrm{QTc}=582 \mathrm{~ms}$

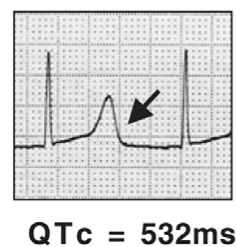

D Control
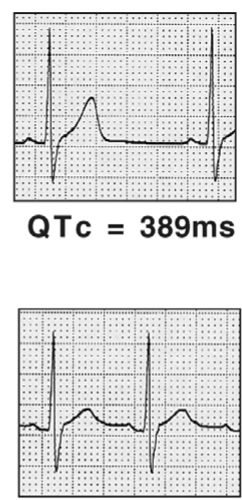

$Q T c=450 \mathrm{~ms}$

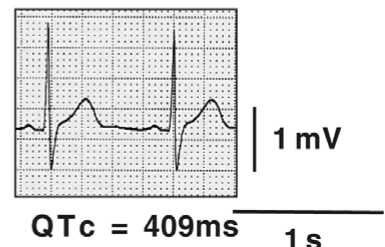

Fig 3. Genotype-specific responses of the corrected QT (QTc) interval to epinephrine provocative testing in patients with LQT1, LQT2 and LQT3 syndromes. Shown are V4 lead electrocardiogram recordings under baseline conditions, at peak and steady-state epinephrine effects in LQT1 (A), LQT2 (B), LQT3 (C) and Control (D) patients. The QTc was prominently prolonged from 576 to $711 \mathrm{~ms}$ at peak epinephrine effect, and remained prolonged at the steady-state $(696 \mathrm{~ms})$ in the LQT1 patient. In the LQT2 patient, the QTc was also markedly prolonged from 592 to $684 \mathrm{~ms}$ at peak, but returned to the baseline level at the steady-state $(611 \mathrm{~ms})$. It was much less prolonged (LQT3: 560 to $582 \mathrm{~ms}$, Control: 389 to $450 \mathrm{~ms})$ at the peak in LQT3 and Control patients than in either the LQT1 or LQT2 patients, and was shortened to the baseline level at the steady-state $(532,409 \mathrm{~ms})$. Modified from Shimizu et al. Heart Rhythm 2004; 1: 276-28317 with permission.

experience cardiac events before age 40 years in the LQT1 and LQT2 syndromes, whereas less than $30 \%$ of patients do so in LQT3 syndrome; however, the lethality of the cardiac events is significantly higher in LQT3 patients than in LQT1 or LQT2 patients. Generally, male patients experience their first cardiac events at a younger age than female patients $5^{50}$ Approximately $90 \%$ of first cardiac events occur before the age of 15 years in male patients, particularly in LQT1 males, whereas female patients do not rarely experience their first cardiac events after the age of $205^{50}$ These tendencies were recently confirmed using the largest cohort of LQT1 syndrome patients ${ }^{1}$ The data suggested that LQT1 males before age 13 years and LQT1 females after age 13 years had a significant and independent clinical risk associated with first cardiac events? 1

Triggers for Cardiac Events Genotype-specific triggers for cardiac events have been reported in patients with LQT1, LQT2 and LQT3 syndromes!2,52,53 Cardiac events occur most frequently during exercise (62\%), and swimming is a common trigger in LQT1 syndrome ${ }^{2}$ LQT2 and LQT3 patients are less likely to have cardiac events during exercise (13\% and $13 \%$, respectively) and more likely to have cardiac events during rest/sleep ( $29 \%$ and $39 \%$, respectively) 52 In LQT2 syndrome, being startled by an auditory stimulus (telephone, alarm clock, ambulance siren etc) is a specific trigger ${ }^{52,53}$ LQT2 women are reported to be most susceptible to cardiac events in the postpartum period $5^{54}$ The differential sensitivity in cardiac events to sympathetic ( $\beta$-adrenergic) stimulation has been suggested to be caused by the differential response of ventricular repolarization to sympathetic stimulation in both experimental studies employing arterially perfused wedge preparations $s^{45,46}$ and in clinical studies using catecholamine provocative testing or exercise testing! ${ }^{6-20}$

\section{Catecholamine Provocative Testing}

Infusion of isoproterenol, a $\beta$-adrenergic agonist, or epinephrine, an $\alpha-+\beta$-adrenergic agonist, has been used as a provocative test in patients with LQTS since the 1980s s. $^{5}$ Before the discovery of distinct genetic subtypes of congenital LQTS, the responses to either epinephrine or isoproterenol were extremely heterogeneous, and deemed impossible to interpret. Now, however, the heterogeneous response is understood to stem from underlying genetic heterogeneity, and genotype-specific responses to epinephrine can be exploited to expose different genotypes of LQTS in its otherwise concealed state, particularly LQT1 syndrome. Although isoproterenol is still used occasionally, recent major insights have been gleaned from using epinephrine. The 2 major protocols developed for epinephrine provocative testing include the escalating-dose protocol by Ackerman's group (Mayo protocol) 18,19 and bolus injection followed by brief continuous infusion by my group (Shimizu protocol)! $16,17,19$

The bolus (Shimizu) protocol was developed on the basis of a differential response of the APD and QT interval to sympathetic stimulation with isoproterenol between experimental models of LQT1, LQT2 and LQT3 using arterially-perfused canine left ventricular wedge preparations ${ }^{46}$ Clinical data from the use of the bolus protocol suggested that sympathetic stimulation produces genotype-specific 


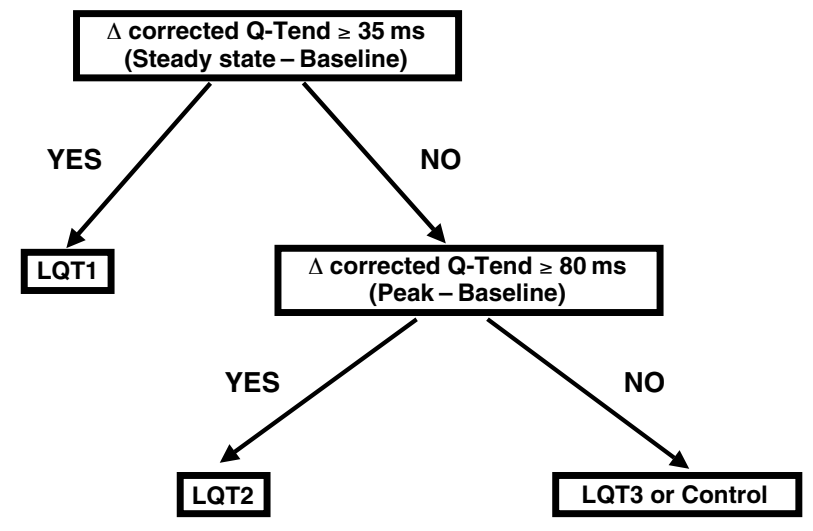

Fig 4. Genotype prediction by epinephrine provocative testing in patients with LQT1, LQT2 and LQT3 syndromes. Flow chart predicting genotype with epinephrine provocative testing. Modified from Shimizu et al. Heart Rhythm 2004; 1: $276-283^{17}$ with permission.

responses of the QTc interval in patients with LQT1, LQT2 and LQT3 syndromes (Fig 3)! ${ }^{16,17,19}$ Epinephrine remarkably prolongs the QTc interval at peak effect when the heart rate is maximally increased (1-2 min after the bolus injection), and the QTc remains prolonged during the steady-state epinephrine effect (3-5 min) in patients with LQT1!6,17,19 In LQT1 patients, a paradoxical QT prolongation, defined as an absolute increase in the QT (not QTc) interval, despite a shortening of the RR interval, is often observed during epinephrine infusion. Ackerman et al reported that the paradoxical QT prolongation had a sensitivity of $92.5 \%$, specificity of $86 \%$, positive predictive value of $76 \%$, and negative predictive value of $96 \%$ for LQT1 patients vs nonLQT1 patients! ${ }^{18}$ In the bolus protocol, QTc is also prolonged at peak epinephrine effect (during bolus) in patients with LQT2, but returns to close to the baseline level at steadystate epinephrine effect ${ }^{17,19}$ In contrast, the QTc is less prolonged at peak epinephrine effect in LQT3 patients than in LQT1 or LQT2 patients, and is abbreviated below the baseline level at steady-state epinephrine effect ${ }^{17,19}$ Using the steady-state epinephrine effect, an improvement of clinical ECG diagnosis (sensitivity) from $68 \%$ to $87 \%$ in 31 patients with LQT1 syndrome and from $83 \%$ to $91 \%$ in 23 patients with LQT2 syndrome, but not in 6 patients with LQT3 syndrome (from $83 \%$ to $83 \%$ ), was reported ${ }^{17}$ The bolus protocol of epinephrine effectively predicts the underlying genotype of LQT1, LQT2 and LQT3 (Fig 4) ${ }^{17,19}$ The prolongation of QTc $\geq 35 \mathrm{~ms}$ at steady-state epinephrine effect can differentiate LQT1 from LQT2, LQT3 or control patients with a predictive accuracy $\geq 90 \%$. The prolongation of QTc $\geq 80 \mathrm{~ms}$ at peak epinephrine effect can differentiate LQT2 from LQT3 or control patients with predictive accuracy of $100 \%$. Although induction of TdP or ventricular fibrillation (VF) is extremely uncommon, intravenous $\beta$-blockers and a cardioverter defibrillator need to be available during testing.

Because molecular diagnosis is still unavailable in many institutes and is time-consuming, a clinical diagnosis of patients with concealed LQTS by epinephrine provocative testing can direct appropriate counseling and facilitate the initiation of preventive measures such as avoidance of QTprolonging drugs. Moreover, a presumptive, pre-genetic diagnosis of either LQT1, LQT2, or LQT3 based on the response to epinephrine can guide genotype-specific treatment strategies.
Table 3 Genotype-Specific Therapy Based on Clinical and Experimental Data in LQTS

\begin{tabular}{lccc}
\hline \hline & $L Q T 1$ & $L Q T 2$ & $L Q T 3$ \\
\hline Prevalence & $40 \%$ & $30-40 \%$ & $10 \%$ \\
Exercise restriction & +++++ & +++ & - \\
$\beta$-blockers & ++++ & +++ & - \\
Potassium supply & $++?$ & ++++ & $++?$ \\
Class IB sodium channel blockers & +++ & +++ & +++++ \\
Calcium channel blockers & +++ & +++ & $++?$ \\
Potassium channel openers & ++ & ++ & - \\
Pacemaker & ++ & ++++ & +++++ \\
ICD & ++++ & ++++ & +++++ \\
\hline
\end{tabular}

ICD, implantable cardioverter-defibrillator; +++++ , most effective. Other abbreviation see in Table 1.

\section{Genotype-Specific Therapy}

Based on the natural history and specific sensitivity to sympathetic stimulation or catecholamine in the LQT1 syndrome, stricter exercise restriction, in particular swimming or diving, is required, especially for LQT1 males!2 Exercise restriction is also required in LQT2 syndrome ${ }^{12}$

Although $\beta$-blockers are empirically believed to be the most effective therapy for patients with congenital LQTS, they are not protective in all LQTS patients. Since molecular genetic studies have become available, genotype-specific pharmacological and non-pharmacological therapies have been introduced clinically, based on data derived from both clinical and experimental studies (Table 3 ).

In LQT1 patients, $\beta$-blockers frequently suppress episodes of syncope and sudden cardiac death ${ }^{52}$ Data from a recent international cohort of 600 LQT1 patients has suggested that time-dependent $\beta$-blocker use is associated with a significant $74 \%$ reduction in the risk of first cardiac events. ${ }^{1}$ Mexiletine, a class IB sodium channel blocker, which blocks late INa, or verapamil, an ICa-L blocker, may warrant consideration as adjunctive therapy to $\beta$-blockers in LQT1 patients, based on ECG changes with these agents or experimental data 44,45 An implantable cardioverter-defibrillator (ICD) is indicated for LQTS patients who have suffered an aborted cardiac arrest and/or who have repetitive episodes of syncope in the presence of $\beta$-blockers.

Beta-blockers are also the first choice as pharmacological therapy in LQT2 patients, but the recurrence rate is higher than in LQT1 patients? ${ }^{2}$ Increase in the extracellular potassium concentration by exogenously administered potassium or long-term oral potassium administration has been reported to shorten the QT interval in LQT2 patients ${ }^{56}$ The indication for an ICD is similar to that in LQT1 syndrome. My group recently reported that patients with LQT2 syndrome show a specific short-long-short initiating pattern of $\mathrm{TdP}$ more frequently than those with LQT1 syndrome;7 so pacemaker therapy is expected to be more effective in LQT2 than in LQT1 patients by suppressing that specific pattern 57

In LQT3 patients, $\beta$-blockers are less effective than in LQT1 or LQT2 patients52 Mexiletine is more effective for abbreviating the QT interval in LQT3 than in LQT1 or LQT2 syndrome, and is therefore a promising therapeutic choice in LQT3 syndrome. Pacemaker therapy may be most beneficial in LQT3 patients with bradycardia, based on the experimental data.

Genotype-specific therapy is unknown for the other forms: LQT4, LQT5, LQT6, LQT7, LQT8, LQT9, LQT10, LQT11, and LQT12. Beta-blockade is the first-line therapy in patients with LQT4, LQT5, LQT6, LQT7, LQT8 and 


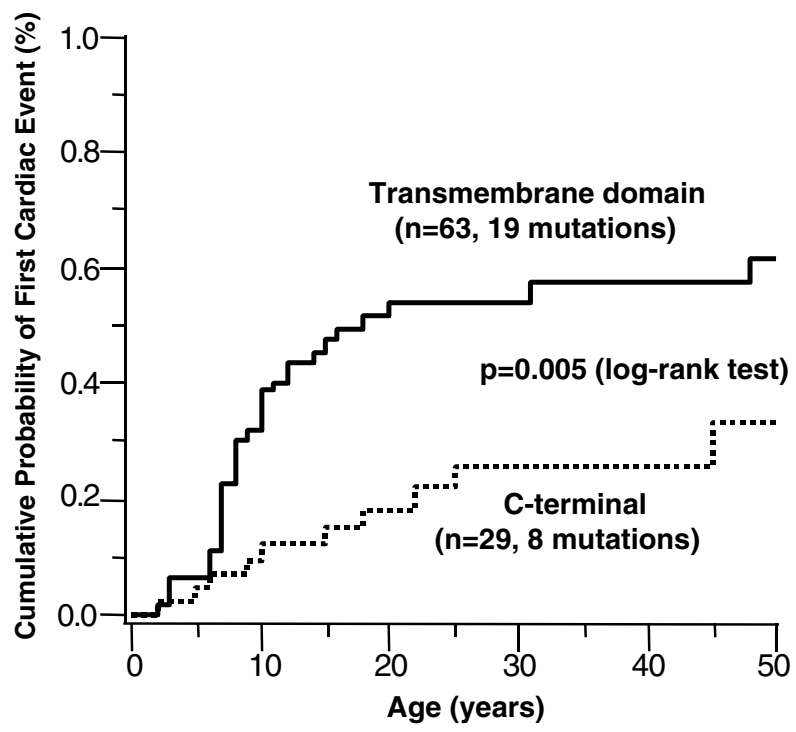

Schematic Representation of KCNQ1

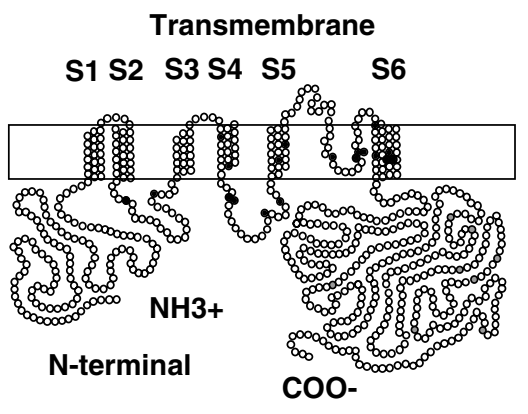

C-terminal

Fig 5. Kaplan-Meier cumulative cardiac event curves from birth to age 50 for patients with $K C N Q 1$ mutations located in transmembrane regions ( $n=66,19$ mutations; closed circles) and the $C$-terminal regions ( $n=29,8$ mutations; gray circles) in LQT1 syndrome. The difference in the clinical course by mutation location was significant (log-rank, $\mathrm{p}=0.005)$, with a greater risk of first cardiac events in patients with transmembrane mutations than in those with C-terminal mutations. Modified from Shimizu et al. J Am Coll Cardiol 2004; 44: 117-12559 with permission.
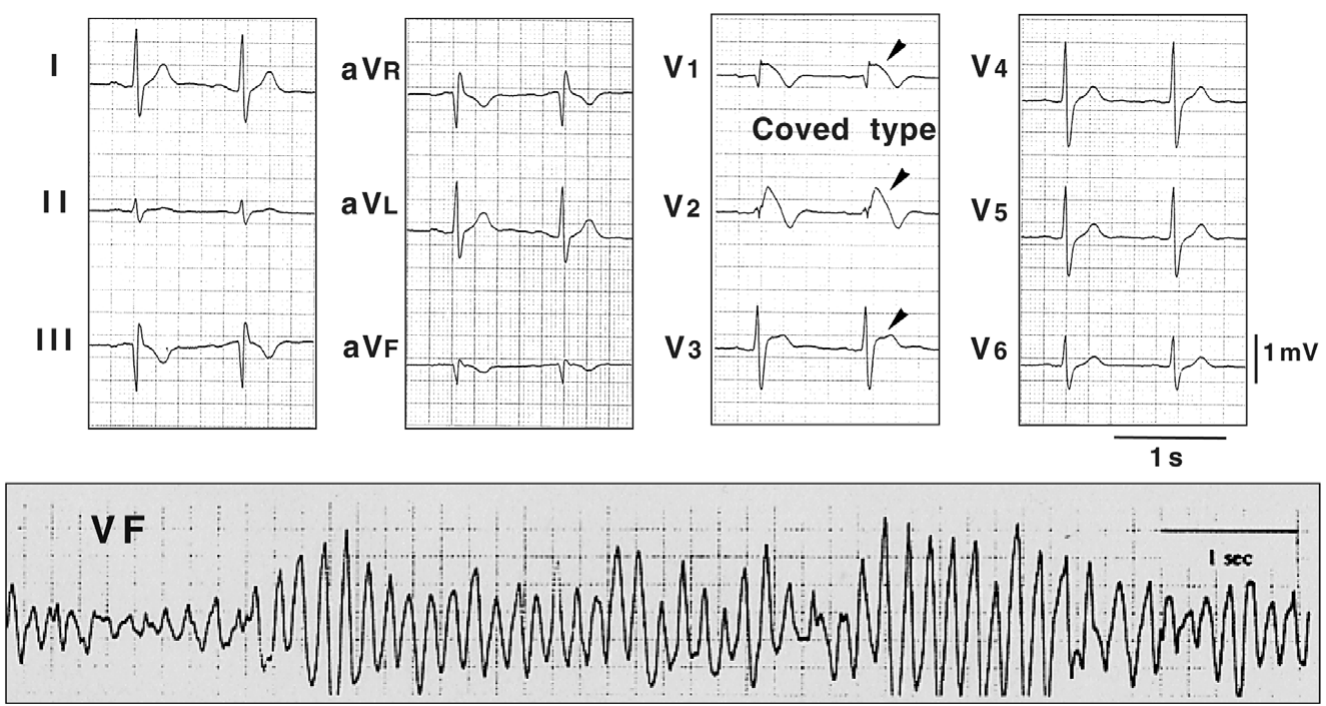

Fig 6. Twelve-lead electrocardiogram and ventricular fibrillation (VF) in a patient with Brugada syndrome. Spontaneous type 1 coved-type ST-segment elevation is recorded in leads $\mathrm{V}_{1}$ and $\mathrm{V}_{2}$ (arrows).

LQT12, and unknown LQTS genotypes. The class IB sodium channel blocker, mexiletine, may be theoretically effective in LQT9, LQT10, and LQT12 patients.

\section{Possibility of Mutation Site-Specific Therapy}

The structure of each cardiac ion channel, or correspondence between the mutation site and channel function, has been increasingly elucidated, suggesting mutation sitespecific differences in the severity of the clinical phenotype or responses to therapy in each genotype. From data in the International LQTS Registry, Moss et al suggested that LQT2 patients with mutations in the pore region of $\mathrm{KCNH} 2$ had a greater risk of arrhythmia-related cardiac events than patients with non-pore mutations ${ }^{58}$ thus indicating the possibility of mutation site-specific management or treatment of
LQT2 syndrome. With regard to LQT1 syndrome, in 2004 the arrhythmic risk and sensitivity to sympathetic stimulation with treadmill exercise testing was compared between Japanese LQT1 patients with transmembrane mutations and those with C-terminal mutations in $K C N Q 1$, and the LQT1 patients with transmembrane mutations showed a longer QTc interval and more frequent LQTS-related cardiac events than those with C-terminal mutations (Fig 5) $5^{59}$ Moreover, the QTc interval was more prominently increased with exercise in patients with transmembrane mutations ${ }^{59}$ The international cohort of 600 LQT1 patients recently confirmed the Japanese data ${ }^{51}$ suggesting that transmembrane mutations and mutations with dominant-negative functional effect adversely influence the outcome of LQT1 patients, independent of traditional clinical risk factors and $\beta$-blocker 
Table 4 Defect of Ion Channel or Membrane Adaptor Responsible for BrS

\begin{tabular}{cccc}
\hline \hline Loci & Chromosome & Gene & Ion channel \\
\hline BrS1 & $3(3 p 21-24)$ & SCN5A & INa \\
BrS2 & $12(12 p 13.3)$ & CACNAIC & ICa-L \\
$B r S 3$ & $10(10 p 12.33)$ & CACNB2 & ICa-L \\
BrS4 & $3(3 p 21)$ & GPDI-L & INa \\
BrS5 & $19(19 q 13.1)$ & SCN1B & $I_{N a}$ \\
BrS6 & $11(11 q 13-q 14)$ & KCNE3 & Ito \\
\hline
\end{tabular}

Abbreviation see in Table 1.

therapy.

\section{Brugada Syndrome}

In 1992, Brugada and Brugada first reported 8 patients with a history of aborted sudden cardiac death caused by VF and a characteristic ECG pattern, consisting of right bundle branch block (RBBB) and ST-segment elevation in the right precordial ECG leads $\left(\mathrm{V}_{1-3}\right)$ as a distinct clinical entity $60-65$ The Brugada Consensus Report in 2002 suggested 3 patterns of ST-segment elevation: ${ }^{63}$ the type 1 ST-segment elevation is characterized by a coved-type ST-segment elevation displaying J-wave amplitude or ST-segment elevation $\geq 0.2 \mathrm{mV}$ with or without a terminal negative $\mathrm{T}$ wave (Fig 6); type 2 and type 3 ST-segment elevations show a saddleback configuration, which has a high take-off ST-segment elevation $(\geq 0.2 \mathrm{mV})$, followed by a gradually descending ST-segment elevation (type $2 \geq 0.1 \mathrm{mV}$, type $3<0.1 \mathrm{mV}$ above the baseline) and a positive or biphasic T wave. STsegment elevation is often accentuated and the coved type ST-segment elevation is more frequently recognized just before and after episodes of VF66,67 The second Consensus Report published in 2005 emphasized that type 1 ST-segment elevation is required to diagnose $\mathrm{BrS}{ }^{64}$ because the type $1 \mathrm{ECG}$ is reported to relate to a higher incidence of VF and sudden cardiac death. Type 1 ST-segment elevation recorded only in the higher (3rd and $2^{\text {nd }}$ intercostal spaces) $\mathrm{V}_{1-2}$ leads is reported to show a similar prognostic value for subsequent cardiac events as that recorded in the standard $\mathrm{V}_{1-2}$ leads ${ }^{64,68-70}$ The prevalence of $\mathrm{BrS}$ is estimated to be up to 5 per 10,000 inhabitants, and is an important cause of sudden cardiac death of middle-aged males, particularly in Asian countries ${ }^{64,65} \mathrm{BrS}$ usually manifests during adulthood, ${ }^{64}$ and more than $80-90 \%$ of patients clinically affected are men.

\section{Genotype in BrS (Table 4)}

In 1998, Chen et al identified the first mutation linked to $\mathrm{BrS}$ in SCN5A, the INa gene that is responsible for the LQT3 form of congenital LQTS3 SCN5A mutations are reported to account for $18-30 \%$ of clinically diagnosed $\mathrm{BrS}$ patients at present ${ }^{6}$ Functional analysis using expression systems has shown that all SCN5A mutations so far identified result in decreased (loss of function) INa by several mechanisms 65 including (1) lack of expression of the sodium channel; (2) a shift in the voltage dependence and time dependence of INa activation, inactivation or reactivation; (3) entry of the sodium channel into an intermediate state of inactivation from which it recovers more slowly; (4) accelerated inactivation of the sodium channel; or (5) a trafficking defect. The 2nd and 3rd mutations linked to BrS were reported by Antzelevitch et al in 2007, when they identified mutations in $C A C N A 1 C$ or $C A C N B 2$, the gene encoding the $\alpha 1$ or $\beta 2 \mathrm{~b}$ subunit of the L-type calcium channel, in 3 probands with Brugada-like ST-segment elevation associated with a short QT interval71 ${ }^{1}$ Heterologous expression studies for the mutations revealed loss of function of ICa-L. Thereafter, London et al identified a mutation in a conserved amino acid of the glycerol-3-phosphate dehydrogenase 1-like (GPD1-L) gene in affected individuals of a large Brugada family?2 The GPD1-L mutation decreases SCN5A surface membrane expression and reduces INa, thus causing BrS?2 Watanabe et al recently identified a nonsense mutation (W179X) in $S C N 1 B$, which encodes the function-modifying sodium channel $\beta 1$ subunit, in a family with $\mathrm{BrS}$ associated with cardiac conduction disease ${ }^{73}$ They reported that the INa current was decreased when $\alpha$ subunit (Nav1.5) of the sodium channel was coexpressed with the mutant $\beta 1$ subunit compared with when it was coexpressed with the wild-type $\beta 1$ subunit. More recently, Delpon, Antzelevitch et al reported a missense mutation (R99H) in KCNE3, which encodes the potassium channel $\beta$ subunit and interacts with Kv4.3 (transient outward current: Ito) channel, in a proband with BrS? ${ }^{4}$ Coexpression of the mutant $K C N E 3$ with $K C N D 3$, which encodes Kv4.3, increases the Ito intensity (gain of function) compared with that by the coexpression of wild-type $K C N E 3$ with $K C N D 37^{4}$ Thus, decreases in the inward sodium or calcium current (late INa, ICa-L) or increases in the outward potassium currents (Ito) produce a Brugada phenotype in all 6 genotypes, as indicated by previous experimental studies; however, approximately two-thirds of Brugada patients have not yet been genotyped, suggesting the presence of genetic heterogeneity 65

\section{Genotype-Phenotype Correlations in $\mathrm{BrS}$}

The genotype-phenotype correlation in $\mathrm{BrS}$ has been less investigated than that in congenital LQTS, because more than two-thirds of patients clinically affected with $\mathrm{BrS}$ are not genotyped. Mild conduction abnormalities, such as widening of the $\mathrm{P}$ wave, prolongation of the $\mathrm{QRS}$ duration, $\mathrm{PQ}$ interval, and $\mathrm{HV}$ interval, and a higher incidence of RBBB have been described in patients with $\mathrm{BrS}$, especially those with the SCN5A mutation64 Significantly longer PQ and HV intervals at baseline and a larger increase in the PQ and QRS intervals after sodium channel blockers have been reported by Smits et al in Brugada patients with SCN5A mutations than in those without SCN5A mutations ${ }^{5}$ Several ECG parameters were measured during long-term follow up and prospectively compared between Brugada patients with and without the SCN5A mutation by Yokokawa and co-workers, with the results suggesting that $\mathrm{P}$ wave, $\mathrm{QRS}, \mathrm{S}$ wave durations, and PQ intervals were all significantly longer, and the $S$ wave amplitude was significantly deeper in the $S C N 5 A$-positive group than in the $S C N 5 A$-negative group (Figs 7,8) ${ }^{76}$ In addition, the PQ interval and QRS duration in lead $V_{2}$ were prolonged more markedly with aging in the 
Brugada patient with SCN5A mutation

A Early period: 1992

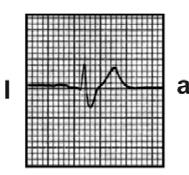

$a V_{R}$

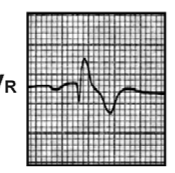

$v_{1}$

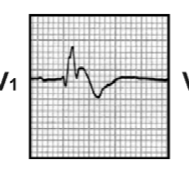

$\mathrm{V}_{4}$
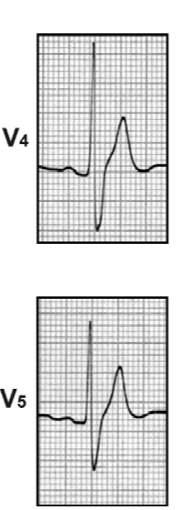

aVL
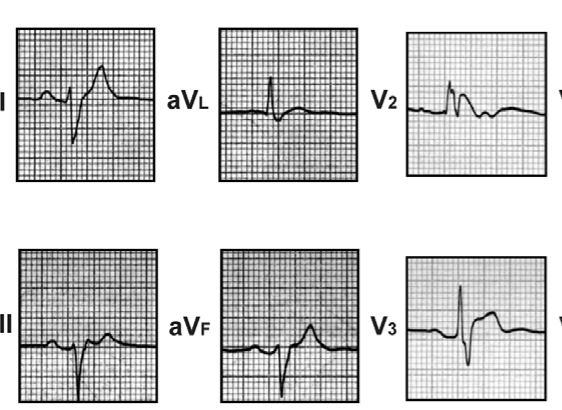

V2-QRS: $142 \mathrm{~ms}$

IIIP: $120 \mathrm{~ms}$ II-PQ: $200 \mathrm{~ms}$

$V_{2}$-QTc: $440 \mathrm{~ms}$

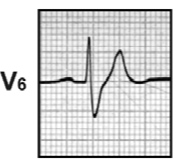

V5-dS: $114 \mathrm{~ms}$
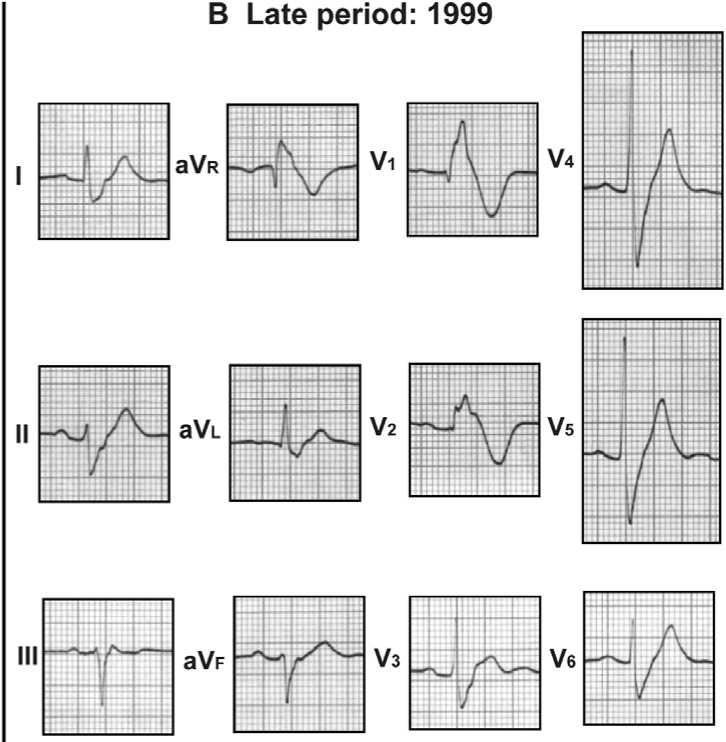

II-P: $137 \mathrm{~ms}$

II-PQ: $229 \mathrm{~ms}$
V2-QRS: $157 \mathrm{~ms}$

V2-QTc: $464 \mathrm{~ms}$

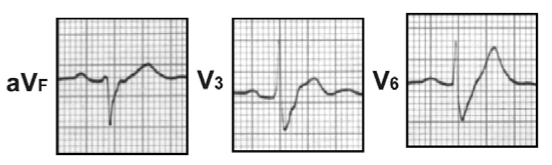

Fig 7. Twelve-lead electrocardiogram in the early and late periods during follow-up (7 years) in a Brugada patient with the SCN5A mutation. The P wave (lead II), QRS (lead V2), and S wave (lead V5) durations and PQ interval (lead II) are prolonged, even in the early period (47 years old) (A). The S wave amplitude (lead V5) is also deep, and the QRS axis is deviated to the left. The corrected QT (QTc) interval (lead $\left.\mathrm{V}_{2}\right)$ is borderline prolonged. In the late period (B), all these parameters are further increased. Modified from Yokokawa et al. Am J Cardiol 2007; 100: 649-65576 with permission.
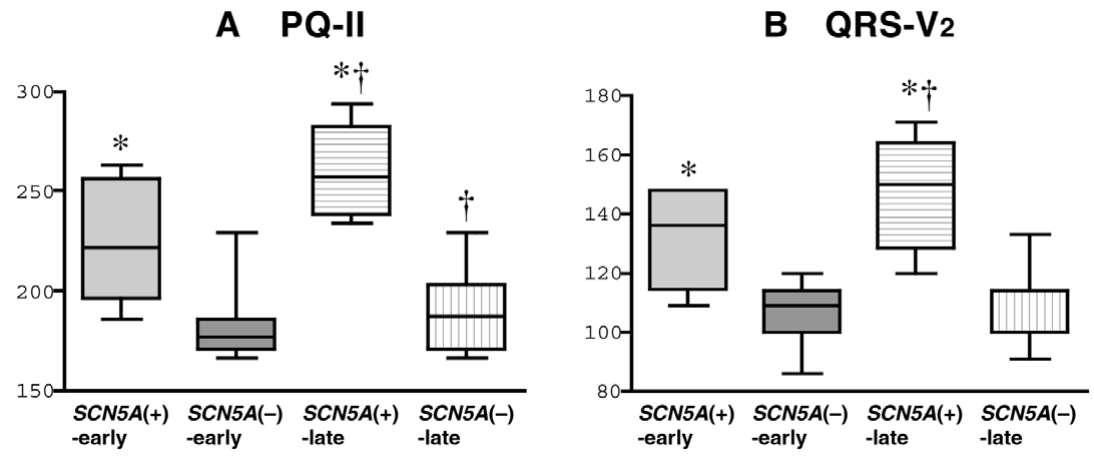

Fig 8. Electrocardiographic parameters during long-term follow-up in 8 Brugada patients with the SCN5A mutation and in 36 Brugada patients without the mutation. Both the PQ interval in lead II (A) and the QRS duration in lead $\mathrm{V}_{2}$ (B) are significantly longer in the $S C N 5 A$-positive (+) group than in the $S C N 5 A$-negative (-) group in both the early and late periods. Both the PQ interval and QRS duration increased with aging during follow-up in both groups, but more prominently in the $S C N 5 A(+)$ group than in the $S C N 5 A(-)$ group. ${ }^{*} \mathrm{p}<0.05$ vs $S C N 5 A(-),{ }^{\dagger} \mathrm{p}<$ 0.05 vs early.
Haplotype A
*Frequency
Haplotype B

\begin{tabular}{|cccccc|}
\hline T & T & T & --- & G & C \\
\hline $\mathbf{C}$ & $\mathbf{C}$ & $\mathbf{G}$ & ins & $\mathbf{C}$ & $\mathbf{T}$ \\
\hline
\end{tabular}
$75.5 \%$
Haplotype C
$24 \%$

\begin{tabular}{|llllll|}
\hline C & T & T & $\cdots$ & C & C \\
\hline
\end{tabular}
$0.5 \%$

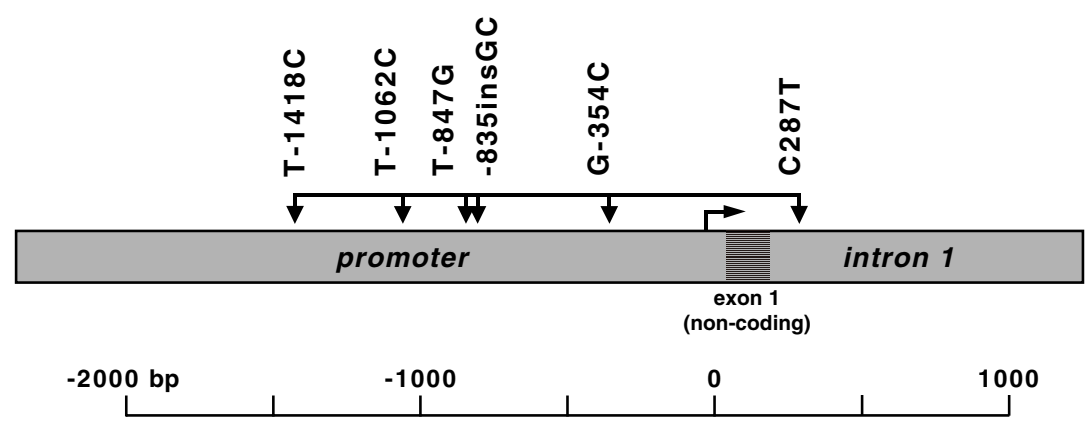

Fig 9. Haplotypes identified within the proximal promoter region of the $S C N 5 A$, a cardiac sodium channel gene. The 6 polymorphisms are in near-complete linkage disequilibrium. Haplotype A is designated as containing all common alleles, and Haplotype B as containing all minor alleles. The discordant haplotype is designated Haplotype C. *Frequency in the Japanese (control) population. Modified from Bezzina et al. Circulation 2006; 113: $338-$ $344^{79}$ with permission. 
A

Brugada
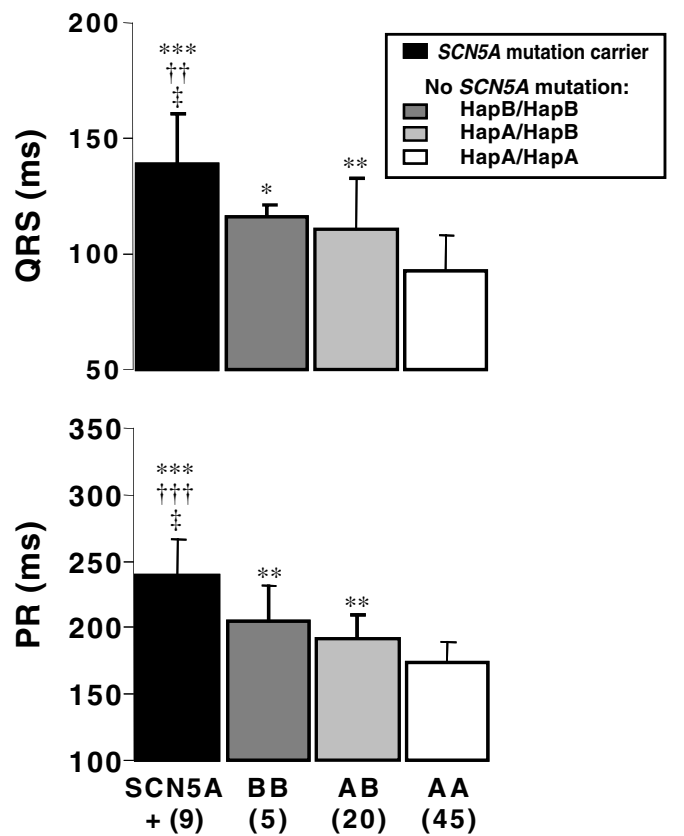

B Control
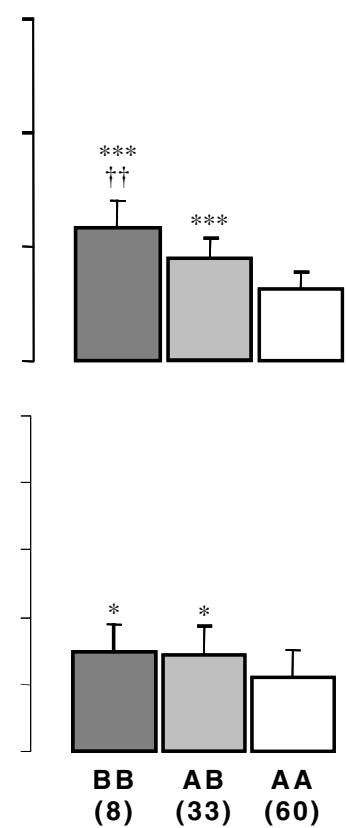

Fig 10. SCN5A promoter haplotype (Hap) pair effects on QRS duration in lead $V_{6}$ and PR duration in lead II in patients with Brugada syndrome and control subjects. In Brugada patients without the SCN5A mutation and in control subjects, both QRS and PR durations show a gene-dose effect, being longest in HapB homozygotes (BB), intermediate in HapA/HapB heterozygotes $(\mathrm{AB})$ and shortest in HapA homozygotes (AA). Brugada patients with the SCN5A mutation show longer QRS and PR durations than those without the SCN5A mutations. Patient numbers are indicated in parentheses. Data are mean \pm SD. Modified from Bezzina et al. Circulation 2006; 113: $338-344^{79}$ with permission. $* \mathrm{p}<0.05 ; * * \mathrm{p}<0.001 ; * * * \mathrm{p}<$ 0.0001 vs HapA/HapA. ${ }^{\dagger}<0.05 ; \dagger p<0.001 ; \dagger p<<$ 0.0001 vs HapA/HapB. ${ }^{\ddagger}<0.05$ vs HapB/HapB.
$S C N 5 A$-positive group than in the SCN5A-negative group during the follow-up period (Figs 7,8$){ }^{76}$ Frustaci et al reported significant myocyte apoptosis in both the right and left ventricular myocardium in a histological study in Brugada patients with SCN5A mutations, and suggested that abnormal function of the sodium channels may lead to a masked degree of cellular damage, contributing to arrhythmic events?7 These electrocardiographic and histologic data indicate that progressive depolarization abnormalities (conduction slowing) with aging may contribute to the pathogenesis of $\mathrm{BrS}$.

\section{SCN5A Promoter Polymorphism}

The incidence of BrS is significantly higher in Asian countries, including Japan, than in the USA and European countries 64 It has been reported that common polymorphisms may modulate the activity of the primary diseasecausing mutation in inherited cardiac arrhythmias, and/or influence the susceptibility to arrhythmia even in the general population ${ }^{78}$ The common polymorphisms are expected to relate to ethnic differences in the clinical phenotype in inherited cardiac arrhythmias, including BrS, because some common polymorphisms are ethnically dependent. A Haplotype B consisting of 6 individual DNA polymorphisms in near-complete linkage disequilibrium within the proximal promoter region of the $S C N 5 A$ gene has been identified in only Asians (allele frequency of $22 \%$ ), but not in Caucasians or African-Americans (Fig 9) ${ }^{79}$ Luciferase reporter activity of the Haplotype B is reduced by $62 \%$ in cardiomyocytes compared with the wild type, Haplotype A.9 The relationship between the $S C N 5 A$ promoter haplotype and indices of conduction velocity, PR and QRS durations was further analyzed in a cohort of 71 Japanese BrS subjects without the SCN5A mutation and in 102 Japanese controls to examine the role of Haplotype B in cardiac conduction. PR and QRS durations were significantly longer in the Haplotype B individuals, with a gene-dose effect in both groups (Fig 10) ${ }^{79}$ Moreover, the increases in both the PR and the QRS dura- tion with sodium channel blockers were genotype-dependent and a gene-dose effect was also observed 79 These data demonstrate that Haplotype B within the $S C N 5 A$ promoter region alone does not give rise to $\mathrm{BrS}$; however, it is possible that the SCN5A promoter Haplotype B contributes to the higher incidence of $\mathrm{BrS}$ in Asian populations, in combination with other as-yet-unknown factors.

\section{Conclusions}

Genetic studies and the genotype-phenotype correlation in lethal inherited cardiac arrhythmias have encouraged cardiologists to perform genotype-specific, so-called tailormade, management and therapy, and possibly mutation sitespecific therapy in patients with genotyped congenital LQTS. Genetic studies are now an important diagnostic tool for stratifying risk and effectively managing and treating genotyped patients. Reflecting the clinical impact of genetic studies in the real world of management and therapy for patients with congenital LQTS, genetic studies to screen for the LQTS gene have been reimbursed by National Insurance in Japan since April 1, 2008. On the other hand, genetic studies of other inherited arrhythmias, including $\mathrm{BrS}$, are still experimental, and further investigations of the genotypephenotype correlations are required.

\section{Acknowledgments}

Dr W Shimizu was supported by the Uehara Memorial Foundation, and health sciences research grants (H18-Research on Human Genome-002) from the Ministry of Health, Labour and Welfare, Japan.

\section{References}

1. Keating M, Atkinson D, Dunn C, Timothy K, Vincent GM, Leppert M. Linkage of a cardiac arrhythmia, the long QT syndrome, and the Harvey ras-1 gene. Science 1991; 252: 704-706.

2. Donger CD, Denjoy I, Berthet M, Neyroud N, Cruaud C, Bennaceur $\mathrm{M}$, et al. KVLQT1 C-terminal missense mutation causes a forme fruste long-QT syndrome. Circulation 1997; 96: 2778-2781.

3. Chen Q, Kirsch GE, Zhang D, Brugada R, Brugada J, Brugada P, et 
al. Genetic basis and molecular mechanisms for idiopathic ventricular fibrillation. Nature 1998; 392: 293-296.

4. Schott JJ, Alshinawi C, Kyndt F, Probst V, Hoorntje TM, Hulsbeek M, et al. Cardiac conduction defects associate with mutations in SCN5A. Nat Genet 1999; 23: 20-21.

5. Priori SG, Napolitano C, Tiso N, Memmi M, Vignati G, Bloise R, et al. Mutations in the cardiac ryanodine receptor gene (hRyR2) underlie catecholaminergic polymorphic ventricular tachycardia. Circulation 2001; 103: 196-200.

6. Laitinen PJ, Brown KM, Piippo K, Swan H, Devaney JM, Brahmbhatt $\mathrm{B}$, et al. Mutations of the cardiac ryanodine receptor (RyR2) gene in familial polymorphic ventricular tachycardia. Circulation 2001; 103: $485-490$.

7. Gerull B, Heuser A, Wichter T, Paul M, Basson CT, McDermott DA, et al. Mutations in the desmosomal protein plakophilin-2 are common in arrhythmogenic right ventricular cardiomyopathy. Nat Genet 2004; 36: $1162-1164$.

8. Chen YH, Xu SJ, Bendahhou S, Wang XL, Wang Y, Xu WY, et al. KCNQ1 gain-of-function mutation in familial atrial fibrillation. Science 2003; 299: 251-254.

9. Veldkamp MW, Wilders R, Baartscheer A, Zegers JG, Bezzina CR, Wilde AA. Contribution of sodium channel mutations to bradycardia and sinus node dysfunction in LQT3 families. Circ Res 2003; 92: 976-983.

10. Schulze-Bahr E, Neu A, Friederich P, Kaupp UB, Breithardt G, Pongs $\mathrm{O}$, et al. Pacemaker channel dysfunction in a patient with sinus node disease. J Clin Invest 2003; 111: $1537-1545$.

11. Brugada R, Hong K, Dumaine R, Cordeiro J, Gaita F, Borggrefe M, et al. Sudden death associated with short-QT syndrome linked to mutations in HERG. Circulation 2004; 109: 30-35.

12. Shimizu W. The long QT syndrome: Therapeutic implications of a genetic diagnosis. Cardiovasc Res 2005; 67: 347-356.

13. Liu N, Ruan Y, Priori SG. Catecholaminergic polymorphic ventricular tachycardia. Prog Cardiovasc Dis 2008; 51: 23-30.

14. Schwartz PJ, Moss AJ, Vincent GM, Crampton RS. Diagnostic criteria for the long QT syndrome: An update. Circulation 1993; 88: 782 784.

15. Moss AJ, Schwartz PJ, Crampton RS, Locati E, Carleen E. The long QT syndrome: A prospective international study. Circulation 1985; 71: $17-21$.

16. Shimizu W, Noda T, Takaki H, Kurita T, Nagaya N, Satomi K, et al. Epinephrine unmasks latent mutation carriers with LQT1 form of congenital long QT syndrome. J Am Coll Cardiol 2003; 41: 633 642 .

17. Shimizu W, Noda T, Takaki H, Nagaya N, Satomi K, Kurita T, et al. Diagnostic value of epinephrine test for genotyping LQT1, LQT2 and LQT3 forms of congenital long QT syndrome. Heart Rhythm 2004; 1: 276-283.

18. Vyas H, Hejlik J, Ackerman MJ. Epinephrine QT stress testing in the evaluation of congenital long-QT syndrome: Diagnostic accuracy of the paradoxical QT response. Circulation 2006; 113: 1385-1392.

19. Shimizu W, Ackerman MJ. Provocative testing in inherited arrhythmias. In: Gussak I, Antzelevitch C, Wilde A, Friedman P, Ackerman MJ, Shen WK, editors. Electrical diseases of the heart: Genetics, mechanisms, treatment, prevention. Springer, UK; 2007; 424-433.

20. Takenaka K, Ai T, Shimizu W, Kobori A, Ninomiya T, Otani H, et al. Exercise stress test amplifies genotype-phenotype correlation in the LQT1 and LQT2 forms of the long QT syndrome. Circulation 2003; 107: $838-844$.

21. Sanguinetti MC, Jiang C, Curran ME, Keating MT. A mechanistic link between an inherited and an acquired cardiac arrhythmia: HERG encodes the IKr potassium channel. Cell 1995; 81: 299-307.

22. Wang Q, Shen J, Splawski I, Atkinson D, Li Z, Robinson JL, et al. SCN5A mutations associated with an inherited cardiac arrhythmia, long QT syndrome. Cell 1995; 80: 805-811.

23. Splawski I, Shen J, Timothy KW, Lehmann MH, Priori S, Robinson JL, et al. Spectrum of mutations in long-QT syndrome genes: KVLQT1, HERG, SCN5A, KCNE1, and KCNE2. Circulation 2000; 102: $1178-1185$.

24. Plaster NM, Tawil R, Tristani-Firouzi M, Canún S, Bendahhou S, Tsunoda A, et al. Mutations in Kir2.1 cause the developmental and episodic electrical phenotypes of Andersen's syndrome. Cell 2001; 105: $511-519$.

25. Mohler PJ, Schott JJ, Gramolini AO, Dilly KW, Guatimosim S, duBell WH, et al. Ankyrin-B mutation causes type 4 long-QT cardiac arrhythmia and sudden cardiac death. Nature 2003; 421: 634-639.

26. Splawski I, Timothy KW, Sharpe LM, Decher N, Kumar P, Bloise R, et al. $\mathrm{Ca}(\mathrm{V}) 1.2$ calcium channel dysfunction causes a multisystem disorder including arrhythmia and autism. Cell 2004; 119: 19-31.

27. Vatta M, Ackerman MJ, Ye B, Makielski JC, Ughanze EE, Taylor
EW, et al. Mutant caveolin-3 induces persistent late sodium current and is associated with long-QT syndrome. Circulation 2006; 114: 2104-2112.

28. Medeiros-Domingo A, Kaku T, Tester DJ, Iturralde-Torres P, Itty A, Ye B, et al. SCN4B-encoded sodium channel beta4 subunit in congenital long-QT syndrome. Circulation 2007; 116: 134-142.

29. Chen L, Marquardt ML, Tester DJ, Sampson KJ, Ackerman MJ, Kass RS. Mutation of an A-kinase-anchoring protein causes long-QT syndrome. Proc Natl Acad Sci USA 2007; 104: 20990-20995.

30. Ueda K, Valdivia C, Medeiros-Domingo A, Tester DJ, Vatta M, Farrugia G, et al; Syntrophin mutation associated with long QT syndrome through activation of the nNOS-SCN5A macromolecular complex. Proc Natl Acad Sci USA 2008; 105: 9355-9360.

31. Wu G, Ai T, Kim JJ, Mohapatra B, Xi Y, Li Z, et al. Alpha-1syntrophin mutation and the long QT syndrome: A disease of sodium channel disruption. Circ Arrhythmia Electrophysiol 2008; 1: $193-$ 201.

32. Sanguinetti MC, Curran ME, Zou A, Shen J, Spector PS, Atkinson DL, et al. Coassembly of KvLQT1 and minK (IsK) proteins to form cardiac IKs potassium channel. Nature 1996; 384: 80-83.

33. Barhanin J, Lesage F, Guillemare E, Fink M, Lazdunski M, Romey G. KvLQT1 and IsK (minK) proteins associate to form the IKs cardiac potassium current. Nature 1996; 384: 78-80.

34. Abbott G W, Sesti F, Splawski I, Buck ME, Lehmann MH, Timothy $\mathrm{KW}$, et al. MiRP1 forms IKr potassium channels with HERG and is associated with cardiac arrhythmia. Cell 1999; 97: 175-187.

35. Schwartz PJ, Crotti L. Can a message from the dead save lives? J Am Coll Cardiol 2007; 49: 247-249.

36. Wedekind H, Smits JP, Schulze-Bahr E, Arnold R, Veldkamp MW, Bajanowski T, et al. De novo mutation in the SCN5A gene associated with early onset of sudden infant death. Circulation 2001; 104: $1158-1164$.

37. Cronk LB, Ye B, Kaku T, Tester DJ, Vatta M, Makielski JC, et al. Novel mechanism for sudden infant death syndrome: Persistent late sodium current secondary to mutations in caveolin-3. Heart Rhythm 2007; 4: 161-166.

38. Rhodes TE, Abraham RL, Welch RC, Vanoye CG, Crotti L, Arnestad $\mathrm{M}$, et al. Cardiac potassium channel dysfunction in sudden infant death syndrome. J Mol Cell Cardiol 2008; 44: 571-581.

39. Splawski I, Timothy KW, Vincent GM, Atkonson DL, Keating MT. Molecular basis of the long-QT syndrome associated with deafness. N Engl J Med 1997; 336: $1562-1567$.

40. Westenskow P, Splawski I, Timothy KW, Keating MT, Sanguinetti MC. Compound mutations: A common cause of severe long-QT syndrome. Circulation 2004; 109: 1834-1841.

41. Priori SG, Schwartz PJ, Napolitano C, Bianchi L, Dennis A, De Fusco $\mathrm{M}$, et al. A recessive variant of the Romano-Ward long-QT syndrome? Circulation 1998; 97: 2420-2425.

42. Bezzina C, Veldkamp MW, van Den Berg MP, Postma AV, Rook $\mathrm{MB}$, Viersma JW, et al. A single $\mathrm{Na}(+)$ channel mutation causing both long-QT and Brugada syndromes. Circ Res 1999; 85: 12061213.

43. Makita N, Behr E, Shimizu W, Horie M, Sunami A, Crotti L, et al. The E1784K mutation in SCN5A is associated with mixed clinical phenotype of type 3 long QT syndrome. J Clin Invest 2008; 118: 2219-2229.

44. Shimizu W, Antzelevitch C. Sodium channel block with mexiletine is effective in reducing dispersion of repolarization and preventing torsade de pointes in LQT2 and LQT3 models of the long-QT syndrome. Circulation 1997; 96: 2038-2047.

45. Shimizu W, Antzelevitch C. Cellular basis for the electrocardiographic features of the LQT1 form of the long QT syndrome: Effects of $\beta$-adrenergic agonists, antagonists and sodium channel blockers on transmural dispersion of repolarization and torsade de pointes. Circulation 1998; 98: 2314-2322.

46. Shimizu W, Antzelevitch C. Differential effects of beta-adrenergic agonists and antagonists in LQT1, LQT2 and LQT3 models of the long QT syndrome. J Am Coll Cardiol 2000; 35: 778-786.

47. Moss AJ, Zareba W, Benhorin J, Locati EH, Hall WJ, Robinson JL, et al. ECG T-wave patterns in genetically distinct forms of the hereditary long QT syndrome. Circulation 1995; 92: 2929-2934.

48. Zhang L, Timothy KW, Vincent GM, Lehmann MH, Fox J, Giuli LC, et al. Spectrum of ST-T-wave patterns and repolarization parameters in congenital long-QT syndrome: ECG findings identify genotypes. Circulation 2000; 102: 2849-2855.

49. Zareba W, Moss AJ, Schwartz PJ, Vincent GM, Robinson JL, Priori $\mathrm{SG}$, et al. Influence of the genotype on the clinical course of the longQT syndrome. N Engl J Med 1998; 339: 960-965.

50. Locati EH, Zareba W, Moss AJ, Schwartz PJ, Vincent GM, Lehmann $\mathrm{MH}$, et al. Age- and sex-related differences in clinical manifestations 
in patients with congenital long-QT syndrome: Findings from the international LQTS registry. Circulation 1998; 97: 2237-2244.

51. Moss AJ, Shimizu W, Wilde AAM, Towbin JA, Zareba Z, Robinson $\mathrm{JL}$, et al. Clinical aspects of type-1 long-QT syndrome by location, coding type, and biophysical function of mutations involving the KCNQ1 gene. Circulation 2007; 115: 2481-2489.

52. Schwartz PJ, Priori SG, Spazzolini C, Moss AJ, Vincent GM, Napolitano C, et al. Genotype-phenotype correlation in the long-QT syndrome: Gene-specific triggers for life-threatening arrhythmias. Circulation 2001; 103: 89-95.

53. Wilde AAM, Jongbloed RJE, Doevendans PA, Duren DR, Hauer RNW, van Langen IM, et al. Auditory stimuli as a trigger for arrhythmic events differentiate HERG-related (LQT2) patients from KVLQT1-related patients (LQT1). J Am Coll Cardiol 1999; 33: $327-332$.

54. Khositseth A, Tester DJ, Will ML, Bell CM, Ackerman MJ. Identification of a common genetic substrate underlying postpartum cardiac events in congenital long QT syndrome. Heart Rhythm 2004; 1: 60 64.

55. Schechter E, Freeman CC, Lazzara R. Afterdepolarizations as a mechanism for the long QT syndrome: Electrophysiologic studies of a case. J Am Coll Cardiol 1984; 3: 1556-1561.

56. Compton SJ, Lux RL, Ramsey MR, Strelich KR, Sanguinetti MC, Green LS, et al. Genetically defined therapy of inherited long-QT syndrome: Correction of abnormal repolarization by potassium. Circulation 1996; 94: 1018-1022.

57. Tan HL, Bardia A, Shimizu W, Moss AJ, Schulze-Bahr E, Noda T, et al. Genotype-specific onset of arrhythmias in congenital long QT syndrome: Possible therapy implications. Circulation 2006; 114: $2096-$ 2103.

58. Moss AJ, Zareba W, Kaufman ES, Gartman E, Peterson DR, Benhorin $\mathrm{J}$, et al. Increased risk of arrhythmic events in long-QT syndrome with mutations in the pore region of the human ether-a-go-go-related gene potassium channel. Circulation 2002; 105: 794-799.

59. Shimizu W, Horie M, Ohno S, Takenaka K, Yamaguchi M, Shimizu $\mathrm{M}$, et al. Mutation site-specific differences in arrhythmic risk and sensitivity to sympathetic stimulation in LQT1 form of congenital long QT syndrome: Multi-center study in Japan. J Am Coll Cardiol 2004; 44: $117-125$.

60. Brugada P, Brugada J. Right bundle branch block, persistent ST segment elevation and sudden cardiac death: A distinct clinical and electrocardiographic syndrome: A multicenter report. J Am Coll Cardiol 1992; 20: $1391-1396$.

61. Antzelevitch C, Brugada P, Brugada J, Brugada R, Shimizu W, Gussak I, et al. Brugada syndrome: A decade of progress. Circ Res 2002; 91: 1114-1118.

62. Priori SG, Napolitano C, Gasparini M, Pappone C, Della Bella P, Giordano U, et al. Natural history of Brugada syndrome: Insights for risk stratification and management. Circulation 2002; 105: $1342-$ 1347.

63. Wilde AA, Antzelevitch C, Borggrefe M, Brugada J, Brugada R, Brugada $\mathrm{P}$, et al. Proposed diagnostic criteria for the Brugada syndrome: Consensus report. Circulation 2002; 106: 2514-2519.

64. Antzelevitch C, Brugada P, Borggrefe M, Brugada J, Brugada R, Corrado D, et al. Brugada syndrome: Report of the Second Consensus Conference: Endorsed by the Heart Rhythm Society and the European Heart Rhythm Association. Circulation 2005; 111: 659-670.
65. Shimizu W, Aiba T, Kamakura S. Mechanisms of disease: Current understanding and future challenges in Brugada syndrome. Nat Clin Pract Cardiovasc Med 2005; 2: 408-414.

66. Kasanuki H, Ohnishi S, Ohtuka M, Matsuda N, Nirei T, Isogai R, et al. Idiopathic ventricular fibrillation induced with vagal activity in patients without obvious heart disease. Circulation 1997; 95: 2277 2285.

67. Matsuo K, Shimizu W, Kurita T, Inagaki M, Aihara N, Kamakura S. Dynamic changes of 12-lead electrocardiograms in a patient with Brugada syndrome. J Cardiovasc Electrophysiol 1998; 9: 508-512.

68. Shimizu W, Matsuo K, Takagi M, Tanabe Y, Aiba T, Taguchi A, et al. Body surface distribution and response to drugs of ST segment elevation in the Brugada syndrome: Clinical implication of 87-leads body surface potential mapping and its application to 12-leads electrocardiograms. J Cardiovasc Electrophysiol 2000; 11: 396-404.

69. Shimizu W, Aiba T, Kamakura S. Mechanism and new findings in the Brugada syndrome. Circ J 2007; 71(Suppl A): A-32-A-39.

70. Miyamoto K, Yokokawa M, Tanaka K, Nagai T, Okamura H, Noda $\mathrm{T}$, et al. Diagnostic and prognostic value of type 1 Brugada electrocardiogram at higher (third or second) V1 to V2 recording in men with Brugada syndrome. Am J Cardiol 2007; 99: 53-57.

71. Antzelevitch C, Pollevick GD, Cordeiro JM, Casis O, Sanguinetti MC, Aizawa $\mathrm{Y}$, et al. Loss of function mutations in the cardiac calcium channel underlie a new clinical entity characterized by ST segment elevation, short QT intervals and sudden cardiac death. Circulation 2007; 115: 442-449.

72. London B, Michalec M, Mehdi H, Zhu X, Kerchner L, Sanyal S, et al. Mutation in glycerol-3-phosphate dehydrogenase 1 like gene (GPD1L) decreases cardiac Na+ current and causes inherited arrhythmias. Circulation 2007; 116: 2260-2268.

73. Watanabe H, Koopmann TT, Le Scouarnec S, Yang T, Ingram CR, Schott JJ, et al. Sodium channel betal subunit mutations associated with Brugada syndrome and cardiac conduction disease in humans. J Clin Invest 2008; 118: 2260-2268.

74. Delpón E, Cordeiro JM, Núñez L, Thomsen PEB, Guerchicoff A, Pollevick GD, et al. Functional effects of KCNE3 mutation and its role in the development of Brugada syndrome. Circ Arrhythmia Electrophysiol 2008; 1: 209-218.

75. Smits JP, Eckardt L, Probst V, Bezzina CR, Schott JJ, Remme CA, et al. Genotype-phenotype relationship in Brugada syndrome: Electrocardiographic features differentiate $S C N 5 A$-related patients from non- SCN5A-related patients. J Am Coll Cardiol 2002; 40: 350-356.

76. Yokokawa M, Noda T, Okamura H, Satomi K, Suyama K, Kurita T, et al. Comparison of long-term follow-up of electrocardiographic features in Brugada syndrome between the SCN5A-positive probands and the SCN5A-negative probands. Am J Cardiol 2007; 100: 649655 .

77. Frustaci A, Priori SG, Pieroni M, Chimenti C, Napolitano C, Rivolta I, et al. Cardiac histological substrate in patients with clinical phenotype of Brugada syndrome. Circulation 2005; 112: 3680-3687.

78. Splawski I, Timothy KW, Tateyama M, Clancy CE, Malhotra A, Beggs AH, et al. Variant of SCN5A sodium channel implicated in risk of cardiac arrhythmia. Science 2002; 297: 1333-1336.

79. Bezzina CR, Shimizu W, Yang P, Koopmann TT, Tanck MWT, Miyamoto Y, et al. A common sodium channel promoter haplotype in Asian subjects underlies variability in cardiac conduction. Circulation 2006; 113: 338-344. 